\title{
Fetal surgical management of congenital heart block in a hydropic fetus: Lessons learned from a clinical experience
}

\author{
Pirooz Eghtesady, MD, PhD, ${ }^{a}$ Erik C. Michelfelder, MD, ${ }^{b}$ Timothy K. Knilans, MD, ${ }^{\mathrm{b}}$ David P. Witte, MD, ${ }^{\mathrm{c}}$ \\ Peter B. Manning, MD, ${ }^{\mathrm{a}}$ and Timothy M. Crombleholme, MD, FACS, FAAP, ${ }^{\mathrm{d}}$ Cincinnati, Ohio
}

Congenital complete heart block (CHB) in the absence of cardiac malformations occurs in approximately 1 in 10,000 live births. ${ }^{1}$ It is the most serious fetal complication of maternal autoimmune disease, leading to antibody-mediated injury of the fetal atrioventricular node and resulting in fetal bradycardia and low output. ${ }^{2,3}$ Hydrops develops in up to $42 \%$ of these fetuses at $27.6 \pm 5.1$ weeks gestation ${ }^{4}$ and is associated with high mortality $(>90 \%)$. Although resolution of hydrops can occur with sympathomimetic treatment, or even spontaneously, a permanent pacemaker is required in approximately $66 \%$ of cases, with placement immediately after birth. ${ }^{4}$ Although fetal pacing has been attempted, there are no reports of survival beyond the intraoperative period.

\section{CLINICAL SUMMARY}

At 20 weeks gestation, a 32-year-old G1P0 (first pregnancy, no previous miscarriages) woman who was positive for Sjogren's antibodies was referred for suspected fetal CHB. Fetal echocardiogram showed absence of atrial mechanical activity; diffuse, predominantly atrial endocardial fibroelastosis (EFE); mild EFE involving the papillary muscle heads and portions of the basal ventricular endocardium; and preserved ventricular systolic function with a ventricular rate of 60 to 70 beats/min. Mitral valve function was normal with trivial tricuspid regurgitation and moderate pericardial effusion. The mother was administered dexamethasone (4 $\mathrm{mg}$ twice daily) and progesterone (200 mg daily).

Echocardiograms at 22, 24, and 25 weeks gestation demonstrated a stable pericardial effusion, continued absence of atrial mechanical activity, and slow ventricular rate $(\sim 50$ beats/min), despite the initiation of maternal terbutaline (24 weeks). At 26 weeks, atrial mechanical activity was detected with an atrial (100 beats/min) and a ventricular (60 beats/min) rate consistent with third-degree block; fetal combined cardiac output measured $405 \mathrm{~mL} / \mathrm{min}^{-1} / \mathrm{kg}^{-1}$

\footnotetext{
From the Division of Cardiothoracic Surgery, ${ }^{\mathrm{a}}$ Division of Pediatric Cardiology, ${ }^{\mathrm{b}}$ Department of Pathology, ${ }^{\mathrm{c}}$ and Fetal Care Center of Cincinnati, ${ }^{\mathrm{d}}$ Cincinnati Children's Hospital Medical Center, Cincinnati, Ohio.

Disclosures: Authors have nothing to disclose with regard to commercial support.

Received for publication Dec 7, 2009; accepted for publication June 28, 2010; available ahead of print Aug 5, 2010.

Address for reprints: Pirooz Eghtesady, MD, PhD, Division of Cardiothoracic Surgery, MLC 2004, Cincinnati Children's Hospital Medical Center, 3333 Burnet Ave, Cincinnati, OH 45229-3032 (E-mail: pirooz.eghtesady@cchmc.org).

J Thorac Cardiovasc Surg 2011;141:835-7

$0022-5223 / \$ 36.00$

Copyright (c) 2011 by The American Association for Thoracic Surgery doi:10.1016/j.jtcvs.2010.06.048
}

(estimated fetal weight $\sim 686 \mathrm{~g}$ ), which was within normal range.

With progression of gestation, fetal hydrops developed (28 weeks; Figure 1, $A$ ), despite a higher dose of maternal steroid therapy. Fetal therapy was discussed with the family, but they elected to continue conservative management. Intravenous maternal isoproterenol was initiated without effect. Reevaluation at 29 weeks revealed a progression of hydrops with a significant increase in the amount of pericardial and ascites
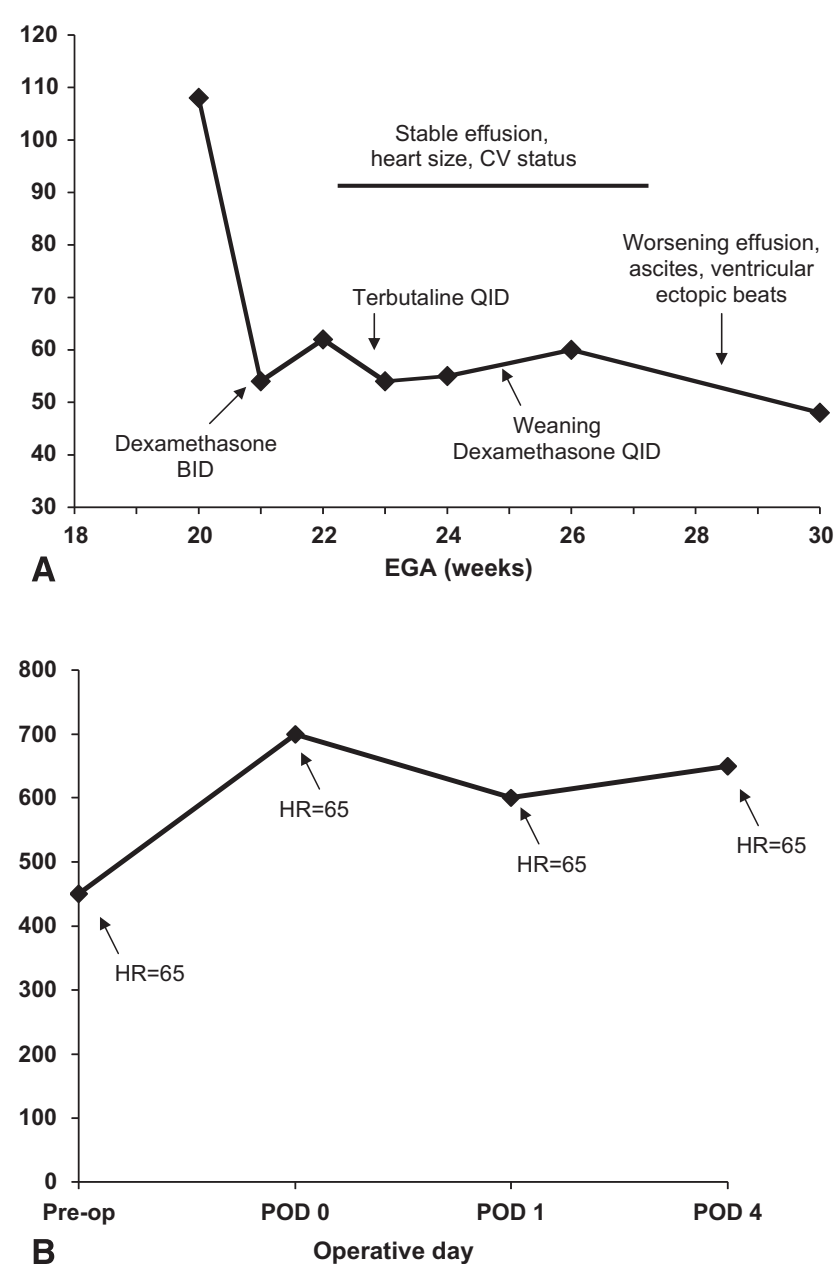

FIGURE 1. A, Fetal heart rate with development of hydrops in a fetus of a mother with systemic lupus erythematosus and anti-Ro and anti-La antibodies. B, Temporal records of combined cardiac output and fetal heart rate generated from weekly echocardiograms over preoperative and postoperative days after pacemaker insertion. Fetal demise occurred on postoperative day 5. $C V$, Cardiovascular; $E G A$, estimated gestational age; $B I D, 2$ times per day; $Q I D$, 4 times per day; $H R$, heart rate; $P O D$, postoperative day. 
fluid. The ventricular heart rate then declined to the mid-40s, and ventricular ectopy became more frequent. The parents elected to undergo emergency open fetal surgery for placement of a fetal cardiac pacemaker.

Maternal anesthesia and posterior hysterotomy according to anterior placental location were performed as described. ${ }^{5}$ Fetal inotropic support was instituted during surgery with significant improvement in fetal cardiac output, further augmented with the placement of a Microny unipolar pacemaker (Medtronics Corp, Minneapolis, MN) via a left thoracotomy. Pericardial, ascites, and left pleural effusions were drained. Ventricular inhibited pacing was initiated with complete ventricular capture at 65 beats/min. Overall, fetal echocardiography showed doubling of the combined ventricular output with good biventricular function during the procedure.

An ultrasound on postoperative day 1 showed the reaccumulation of small amounts of fetal ascites and the presence of mild oligohydramnios. Fetal cardiac output had increased approximately $150 \%$ compared with prepacemaker studies (Figure 1,B). On postoperative day 2, communication with the device was attempted to increase fetal pacing rate, but this was not successful via an abdominal approach or repositioning of the mother to alter the fetal position. Oligohydramnios continued, but there was no evidence of fluid discharge per vagina or intra-abdominal accumulation to account for amniotic fluid loss. Therefore, maternal dexamethasone was decreased on postoperative day 4 from 2 to $1 \mathrm{mg}$ daily. The oligohydramnios persisted, suggestive of decrease fetal kidney function, and on postoperative day 5 sudden fetal demise was noted.

Autopsy showed the fetus weighed $1515 \mathrm{~g}$ and had mild anasarca. The preterm placenta weighed $350 \mathrm{~g}$. The fetal pacemaker and lead were intact and in the proper location, without gross evidence of epicardial injury. The cardiac chambers were dilated, thin-walled, with diffuse evidence of EFE and dystrophic calcification (Figure 2). There was also evidence of chronic liver failure. Mild pulmonary hypoplasia together with congestion and petechiae were noted in multiple organs. In addition, evidence of long-standing injury was apparent in the kidneys (necrosis and fibrosis), and severe stress involution of the thymus and adrenal glands was apparent. The intrauterine fetal demise seemed to be the result of chronic multiorgan failure.

\section{DISCUSSION}

The mechanisms leading to hydrops in CHB remain unknown. A simple explanation may be that a threshold heart rate is necessary, below which cardiovascular comprise develops. Hydropic fetuses have lower heart rates during pregnancy than non-hydropic fetuses, ${ }^{4}$ and rates less than 50 beats/min and development of fetal hydrops are associated with increased mortality. Our case also illustrates the overall
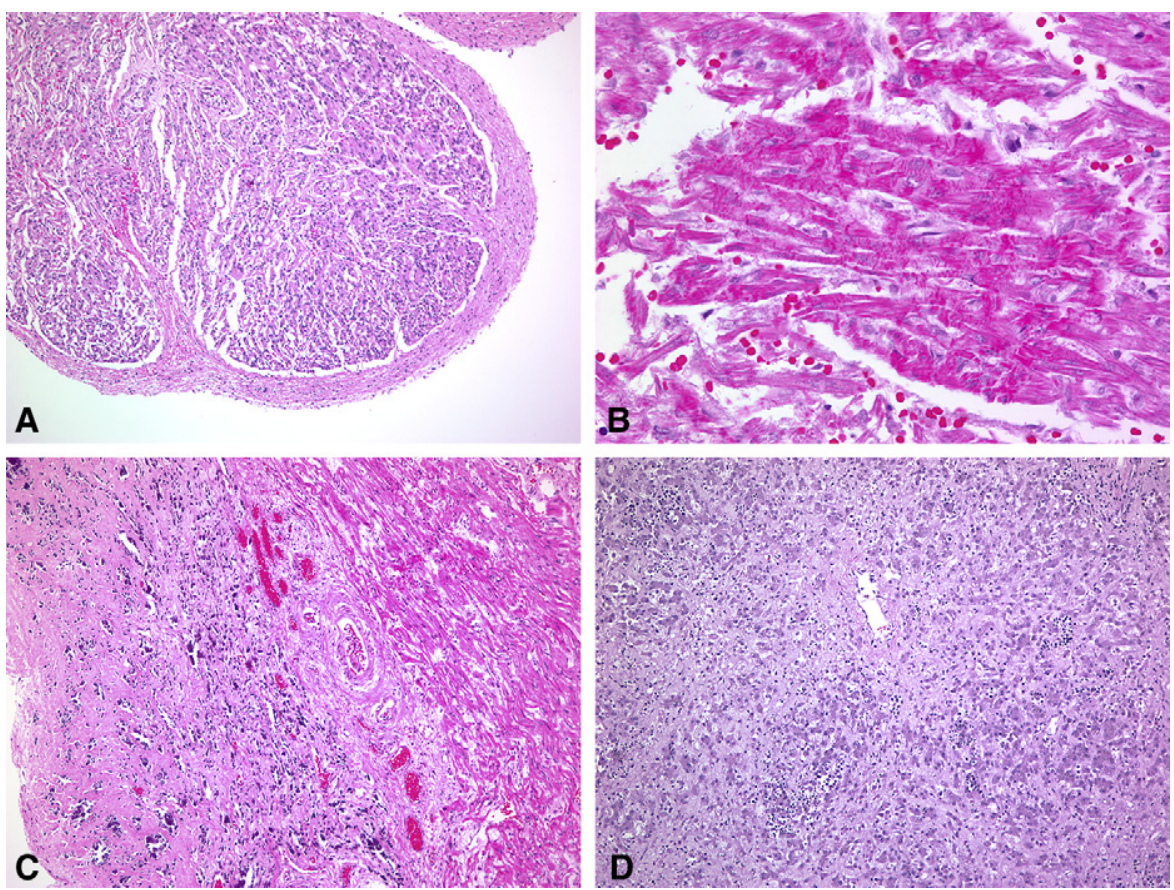

FIGURE 2. A, Sections from the right ventricle show prominent endocardial sclerosis and uniformly thickened layers of fibroelastic stroma (hematoxylineosin magnification 10×). B, The left ventricular myocardium shows necrosis with loss of cytoplasmic detail and increased eosinophilia (hematoxylin-eosin magnification $40 \times$ ). C, The epicardial surface (right half of picture) shows extensive dystrophic calcification and fibrosis (hematoxylin-eosin magnification $10 \times)$. D, The liver shows evidence of severe chronic passive congestion of the lobule. There is extensive atrophy of the hepatic chords, sinusoidal fibrosis, and prominent extramedullary hematopoiesis in the sinusoids. 
inefficacy of current medical regimens in this scenario. In addition, CHB is an autoimmune process that can be associated with damage to the myocardium itself. Thus, an underlying cardiomyopathy affecting cardiac output may play a primary or secondary role in developing hydrops. The impact of fetal inotropic support in our case highlights this point. Our case also illustrates the limitation of altering the pacemaker rate in the postoperative period with current technology. Further, our case demonstrates the limitations of serial weekly fetal echocardiograms and the potential for rather precipitous development of hydrops. Indeed, the findings of chronic multiorgan failure in the postmortem study of our patient highlight the importance of early intervention in these babies, that is, at the very first signs of hydrops.

\section{CONCLUSIONS}

Future research aimed at earlier, noninvasive detection of cardiac failure and organ-system compromise will improve outcomes. Controversial ethical issues and questionable medical indications of open fetal surgery, significant morbidity to the mother, and risks associated to the pregnancy, as well as to future fertility and pregnancies, need to be recognized.

\section{References}

1. Michaelsson M, Engle MA. Congenital complete heart block: an international study of the natural history. Cardiovasc Clin. 1972;4:85-101.

2. Askanase AD, Friedman DM, Copel J, et al. Spectrum and progression of conduction abnormalities in infants born to mothers with anti-SSA/Ro-SSB/La antibodies. Lupus. 2002;11:145-51.

3. Nield LE, Silverman ED, Smallhorn JF, et al. Endocardial fibroelastosis associated with maternal anti-Ro and anti-La antibodies in the absence of atrioventricular block. J Am Coll Cardiol. 2002;40:796-802.

4. Breur JM, Kapusta L, Stoutenbeek P, Visser GH, van den Berg P, Meijboom EJ Isolated congenital atrioventricular block diagnosed in utero: natural history and outcome. J Matern Fetal Neonatal Med. 2008;21:469-76.

5. Kitano Y, Flake AW, Crombleholme TM, Johnson MP, Adzick NS. Open fetal surgery for life-threatening fetal malformations. Semin Perinatol. 1999;23: 448-61.

\title{
Norwood procedure using modified Blalock-Taussig shunt: Beware of the circle of Willis
}

\author{
Selma O. Algra, MD, ${ }^{\mathrm{a}}$ Floris Groenendaal, MD, ${ }^{\mathrm{b}}$ Ton Schouten, MD,${ }^{\mathrm{c}}$ and Felix Haas, MD, ${ }^{\mathrm{d}}$ Utrecht, \\ The Netherlands
}

Neonates undergoing complex cardiac surgery are at high risk of developing cerebral damage. ${ }^{1}$ In the past decades, surgical and cardiopulmonary bypass strategies have been modified to improve neurodevelopmental outcome. One example is the introduction of antegrade cerebral perfusion (ACP) during aortic arch repair, instead of deep hypothermic circulatory arrest. Although it is not yet known whether this indeed is a superior strategy, ACP is now widely used in congenital heart surgery. ${ }^{2}$ This case report shows that when ACP is performed, cerebral near-infrared spectros-

\footnotetext{
From the Department of Pediatric Cardiothoracic Surgery and Intensive Care, ${ }^{\mathrm{a}} \mathrm{De}$ partment of Neonatology, ${ }^{b}$ Department of Pediatric Intensive Care, ${ }^{c}$ and Department of Pediatric Cardiothoracic Surgery, ${ }^{\mathrm{d}}$ University Medical Center Utrecht, The Netherlands.

Disclosures: Authors have nothing to disclose with regard to commercial support.

Received for publication May 25, 2010; accepted for publication June 28, 2010; available ahead of print July 26, 2010.

Address for reprints: Selma O. Algra, MD, Department of Pediatric Cardiothoracic Surgery and Intensive Care, University Medical Center Utrecht, In-house post KG.01.3190, Lundlaan 6, 3584 EA Utrecht, The Netherlands (E-mail: s.o. algra@umcutrecht.nl).

J Thorac Cardiovasc Surg 2011;141:837-9

0022-5223/ $\$ 36.00$

Copyright (c) 2011 by The American Association for Thoracic Surgery

doi:10.1016/j.jtcvs.2010.06.049
}

copy (NIRS) can provide important information about the circle of Willis, which may influence the surgical strategy.

\section{CLINICAL SUMMARY}

A term infant presented with double inlet left ventricle, transposition of the great arteries, and obstruction of the aortic arch. He was scheduled to undergo the Norwood procedure. According to our standard protocol, cerebral magnetic resonance imaging was performed the day before surgery and NIRS electrodes were placed on both sides of the forehead, showing similar values on the right and left hemispheres (mean regional oxygen saturation $76 \%$ on the right and $72 \%$ on the left).

During surgery, a modified Blalock-Taussig (BT) shunt was placed on the brachiocephalic artery, just distal of the bifurcation, to perform ACP $(43 \mathrm{~mL} / \mathrm{kg} / \mathrm{min})$. During this period (50 minutes), right NIRS was continuously $20 \%$ higher than left NIRS (mean right, 92\%; left, 72\%). After arch repair, full cardiopulmonary bypass was resumed and right and left NIRS values approximated each other. However, when the patient was weaned from bypass, asymmetric NIRS values emerged again, but now with lower NIRS values on the right hemisphere. NIRS was monitored until 48 hours 